\title{
Some Problems of Teaching Russian Literature to Foreign Students
}

\author{
Ekaterina A. Artemeva \\ Mari State University \\ Yoshkar-Ola, Russia \\ artemeva_ea@marsu.ru
}

\author{
Elena G. Tonkova \\ Mari State University \\ Yoshkar-Ola, Russia \\ eltonkova@yandex.ru
}

\author{
Alevtina G. Lavrentieva \\ Mari State University \\ Yoshkar-Ola, Russia \\ aglavr@yandex.ru
}

\begin{abstract}
The article considers problems of teaching and interpreting authentic literary texts in the history of Russian literature classes for non-native Russian speakers from the Central Asia region. The study describes criteria for selecting literary texts, including the culturological dimension. It is concluded that the teaching of Russian literature for non-native Russian speakers should consider the ethnocultural characteristics of students in connection with Russian as a foreign language in other literary disciplines in their educational program. The article also assumes that students from the Central Asia region demonstrate the ability to adequately perceive complex modernist authentic texts with rich cultural content, as they are characterized by a harmonious combination of personal values and high adaptability to the Russian cultural context.
\end{abstract}

Keywords-Russian as a foreign language, methods of teaching literature, methods of literature teaching in the aspect of Russian as a foreign language, linguoculturology, classical literature

\section{INTRODUCTION}

\section{A. Actualizing the problem}

In working with foreign students who learn Russian language, literature, culture and/or history literary texts constitute the most central and significant challenge. Literature can provide a powerful tool that helps in developing and improving communicative and intercultural skills. The methodology of teaching reading to non-native speakers of Russian has been studied quite seriously by A.N. Vasilyeva [1], M.G. Knipper and V.Y. Rosenzweig [2], L.S. Zhuravleva and M.D. Zinovieva [3], T.E. Pecheritsa [4], I.K. Gapochka [5], A.V. Brygina [6], I.G. Gubieva and V.A. Yacelenko [7], Y.L. Berezovskaya and O.I. Sharafutdinova [8], A.V. Rachkovskaya [9], M.P. Chesnokova [10] and others.

In their practice, teachers of Russian as a foreign language use frequently adapted Russian literature and news media where cultural elements are reduced since these are most commonly considered to be difficult parts of a text. According to A.V. Brygina, the adapted literary text is "a secondary text derived from the original source, which, having with the source text the unity of subject matter and story basis, has been transformed by combining some linguistic and nonlinguistic techniques to achieve effective communication goals" [6]. Adapted literary texts are always explored for specific purposes, they are primarily intended to be used for lexical and grammar learning or for information and contentbased analysis.

At present, methodological principles of authentic texts selection and adaptation are widely studied in academic research and tested in teaching practice. T.M. Dridze described the construction of a hierarchy of content elements of fictional text by information-targeted analysis [11], T.E. Pecheritsa applied the theory in practice to adapt fictional texts for teaching foreign language [4]. The value of such an approach is that it makes it possible to present the hierarchy of communicative meanings of the literary text. The study by E.V. Dziuba and S.A. Eremina summarizes the main techniques of compositional-content and/or language adaptation of Russian literary text, among which the researchers selected inversion, replacement, reduction, addition [12]. However, there are texts for which the construction of such a hierarchy of meanings and reducing any language element can be highly controversial.

In practice, when selecting the fiction text for the literature class, the teacher has to constantly choose a criterion, often to the detriment of other methodological priorities: authenticity, language accessibility, informativity and representativeness for the literary process. Nowadays, the focus of foreign language teaching methodology is on cultural aspect. Reading authentic fictional texts helps non-native readers to enhance their cultural knowledge, which is crucial for acquiring language competence. As H. Douglas Brown shows, "second language learning is often second culture learning" [13]. Also, teaching Russian as a foreign language suggests a formation of intercultural competence based on understanding the national cultural realities through authentic texts. As a result, foreign students works out intercultural world outlook, empathy, tolerance and acknowledgement of cultural diversity. Adapted texts do not allow a full immersion into the extremely rich 
world of national literature, history and culture. For those students who aim not only to learn Russian, but also to get acquainted with the history of Russia, its culture and achievements, reading authentic texts are essential. In recent years, a number of Russian literature textbooks appeared, which offer reading authentic fiction texts $[14,15,16,17,18$, 19].

\section{B. Status of a problem}

Primarily, these students include those who study to be a teacher of Russian as a foreign language. Their educational program involves Russian literature classes. Teachers of this discipline are fully aware of the special role of culturological commentary for interpreting authentic literary text.

There is no doubt that, in selecting the texts to be read and interpreted by foreign students, a teacher should consider their potential linguistic and cultural complexity for a non-native reader, who is not included in the cultural space where their author and Russian native speakers are located. In this context, the cultural space is understood as "the form of the existence of culture in the consciousness," which "includes all existing and potentially possible notions of cultural phenomena among the members of some national cultural community" [20]. Thus, it is absolutely necessary to consider the text not only as a means of language teaching and learning, possessing significant ideological and thematic content, genre and compositional originality, and playing a significant role in the literary process, but also as an important carrier of "information about history, ethnography, national psychology, national behavior, that is, everything that constitutes the content of culture" [21].

It is also vital to emphasize the fact that when reading authentic Russian literary texts, students bring their cultural background in analyzing, since they cannot be culturally neutral, they are always plunged in their own culture. However, it is well-known that different cultures can share common values. Non-native readers of Russian who belong to a cultural space having border crossing points with Russian culture context, can not only adapt more easily to Russian reality, but can also have a greater inclination toward understanding complex, authentic literary texts. For example, an analysis of student value orientations at the Peoples' Friendship University of Russia (RUDN) in 2012 shows that students from the Central Asia region have the best adaptation to Russian cultural realities and the most balanced combination of beliefs and value orientations (by comparison, students from China and the Middle East are the most unstable) [22]

\section{METHODS AND MATERIALS}

\section{A. The tasks of the research}

The tasks of the research are: 1) to offer text selection criteria for students from Central Asia; 2) to identify the difficulties that may arise while reading the Russian authentic texts.

\section{B. Theoretical and empirical methods}

The following methods were used during the study:

- theoretical: analysis of the scientific and methodological literature on the problem;

- empirical: observation and description, text mining approach

\section{RESULTS}

When selecting authentic literary texts for non-native readers of Russian, a key consideration is a combination of following factors: "small volume (which is convenient for holistic analysis), representativeness (possibility to demonstrate with the help of texts the most characteristic phenomena in the Russian literary process), difficulty of interpretation of the text along with its lexical-grammatical accessibility" [23]. Small volume is a very important requirement for the text. Programs on Russian literature for native readers of Russian and for Russian language learners, even of advanced level, should be different. V.V. Aguenosov states that "it seems appropriate at the slightest opportunity to replace long texts with short stories, that give ideas about the artistic world of the writer" [24]. Some modern manuals respect this principle (Zheng Tiwu and Hao Ruoqi mention this successful practice, saying that in modern Chinese chrestomathics on Russian literature fragments of the novels "War and Peace" and "Anna Karenina" by L.N. Tolstoy are already replaced with the story "The Death of Ivan Ilyich" [25]). Moreover, if a teacher recommends for reading too long text to foreign students, often they fight against temptation of reading only its plot summary, which is categorically unacceptable.

Language proficiency is another crucial parameter that should be taken into account in the selection of literary works. The practice of Russian language and literature teaching in groups of students from Turkmenistan, Uzbekistan, Tajikistan testifies to their ability to understand and analyze complex texts, due to the specificity of their ethnic, national, and personal background. In these countries, Russian is the language of inter-ethnic communication and is generally studied in secondary school, so students are quite well prepared for studying Russian language and literature at university in advanced Russian learners groups. In any case, they overcome cultural and linguistic barriers rather successfully.

When selecting a text for reading, the teacher should also consider its subject matter and potential fascination for students: "When selecting texts, it is necessary to choose those that are close to modern students' interests" [24]. N.V. Kulibina suggested reading texts that "in the future would create a stable motivation for reading fiction in Russian: poetry and prose, classics and modern literature, detectives and fiction, monologues of satirical writers, etc." [26]. If, for example, Iraqi students show interest in texts of revolutionaryliberation and military-patriotic topics [27], students from Turkmenistan, Uzbekistan, Tajikistan successfully analyze philosophical fiction, as well as show great interest in detective stories and melodramatic plots. Their favorite themes 
are family, community, compassion, love, friendship, and other values. Students from Turkmenistan, Uzbekistan, Tajikistan also show notable interest in the biography of writers, their human qualities, moral search and contradictions.

Turn-of-the-century literary texts (short stories by I.A. Bunin, A.I. Kuprin, I.S. Shmelyov, A.M. Remizov, V.V. Veresaev, A.S. Grin, M.A. Bulgakov, Y.K. Olesha, K.G. Paustovskij) might be therefore efficient and challenging in terms of understanding by non-native speakers of Russian from the Central Asia region, since these represent the standard of speech realization of language norm and contain rich cultural material. Moreover, it was at the turn of the 19th and 20th centuries that intra-literary and general cultural processes led to a gradual increase in the number of short stories. This fiction makes it possible to consider such turn-ofthe-century literary phenomena as convergence of realism and modernism, preservation of humanistic values in the context of the crisis of rationalism, emergence of new aesthetic forms, since modernist literature is characterized by a self-conscious break with conventional ways of writing, in prose fiction and poetry.

For most foreigners, Russian literature is still limited to the major works by Pushkin, Gogol, Dostoyevsky, Tolstoy, Chekhov, but the unique phenomenon of the Silver Age stays unknown until today. N.G. Chekalina assumes that turn-ofthe-century poetry is highly suitable for advanced learners of Russian [28]. As she shows, due to specific characteristics, poetic structure, core motifs, and images, Silver Age lyric poems provide stimulating challenges for advanced Russian language learners.

Nevertheless, there are certain nuances of selecting short literary texts. For exemple, in our practice, students analyze short stories such as "The Gentleman from San Francisco" and "Light Breathing" by I.A. Bunin much more successfully than his "Antonov Apples". The symbolic and conceptual unity of "The Gentleman from San Francisco", as well as its parable content and certain national and thematic neutrality, make possible its interpretation by non-native readers of Russian. The teacher should point to the connection of the piece with "Brothers" and "The Dreams of Chang" by I.A. Bunin, which are also successfully analyzed by foreign students, and encourage them to discuss the story's place in the canon of Russian (for example, Thomas Mann noted that "The Gentleman from San Francisco" could be compared with Tolstoy's books by its moral power) and world literatures (for a more rounded view, it is also pertinent to compare "The Gentleman from San Francisco" and "Death in Venice" by Thomas Mann)

The fairy-tales by A.M. Remizov are notable for their exploration of national cultural identity. However, these texts, due to their pronounced moral content and references to Russian magic fairy tale, can also be recommended for reading by students. For example, when guiding students to read the fairy tale "Zaychik Ivanich" the teacher should point out the references to the Russian magic fairy tales (in the Comparative Index of stories it is 311 "The Bear and the Three Sisters"), as well as to the image of a hare (zajchik, zain ka) in Russian culture.
Some authentic literary texts cause special difficulties in reading among non-native readers of Russian. Despite the fact that such emotion as laughing belongs to the universals of human existence, humorous literature contains an ethnocultural component, since at the communicative level "the understanding of the joke is incorporated into the general context of culture" [29]. It is for this reason that the humorous stories by Chekhov had been staying non-translated for a long time, so the writer had the image of a serious, pessimist author [30].

The study of nature of the comic is difficult because there is still no universal and full definition of comic. Its appearance is hardly possible being that this sense is very subjective and historically has been fluid. After a certain time, many events that raised a laugh stop to be funny. The study of linguistic comic means can give interesting results because lingual game is a linguistic irregularity that writer well knows and he does it purposely.

Characterizing the stories by A.P. Chekhov, V.B. Kataev uses the word combination "complexity of simplicity" [31], explaining it, among other things, by the specificity of Chekhov's humor (for example, mismatch between the tragedy of the plot and the humorous form; satirical depiction of social conflict; specificity of dialogues and speech characteristics of heroes; active use of speaking names, etc.). Thus, in his early humorous stories Chekhov considers social problems of a certain type. Thus, one of the most developed problems is the arbitrariness of official power, presented in "The Thick and the Thin", "The Death of a Clerk", "The Chameleon", "Sergeant Prishibeyev". These stories distinguished by a lack of sympathy, a mockery, "unsentimental attitude (....) towards the suffering side in the satirical conflict" [ibid.]. In this way, they strongly contrast with the tradition of depicting a "little man" in Russian literature, which requires a delicate and careful explanation from the teacher. Also, it is worth drawing the attention of students to the fact that some Chekhov's stories gave rise to certain precedent phenomena ("the thick and the thin," "the man in the case," "the lady with the dog," "unterprishibeevshhina," etc.) and describe their importance in modern culture.

Finally, modern students, not only foreign but also native speakers of Russian, see the literary text as primarily a source of information. Russian literature teacher should therefore motivate them to perceive literature as an aesthetic phenomenon. Students, especially those who are future Russian language and literature teachers, should also master literary terminology. Many literary terms that Russian students generally learn at school (composition, plot, humor, epithet, metaphor, simile, etc.) are unknown to foreign students. It is turn-of-the-century literary texts that offer great opportunities for learning literary tropes.

\section{DISCUSSION}

Thus, the teacher selects the text from the point of view of its comprehensibility and substantial attractiveness. He should consider that the works of art were created in that era when the Russian language was different. The syntax of the language 
has changed since then. Nowadays the carriers of the Russian language prefer to save speech effort, therefore they choose simple syntactic constructions and often use elliptical sentences in their speech.

In contrast, the stories by I.A. Bunin are distinguished by an abundance of complex syntactic structures and complicated sentences that have to be commented by the teacher. The texts by I.S. Shmelyov reveal the peculiar narrative format that will not be understood by the foreign students. That's why the teacher should comment the grammatical (morphological and syntactic), spelling deviations from the speech standard that are part of the author's artistic design.

The literary texts written in the 19th century and at the turn of the 19th and 20th centuries are commonly incomprehensible even to modern native speakers of Russian. Therefore, the teacher of Russian literature and culture should develop his competence in the field of linguistic commentary. His professional tasks include working with culture-specific vocabulary, explaining Russian agnonyms, organizing work with words that characterize the certain era, denote wordrealities that are not characteristic of the 21 st century.

To successfully achieve the goal of teaching the foreign students, the teacher of Russian literature needs to use dictionaries of the Russian language, which fix the departed and outgoing words and also the meanings of words, and in some cases, to compose such vocabularies for work in the practical classes. It should also give cultural information about the realities that were designated by these words, in order to create a holistic picture of the life of Russian society in certain epochs.

The Russian literature gives the researchers an opportunity to study language phenomenon always. It is essential, since the Russian vocabulary constantly changes. In practice the students can find in the texts a number of the interesting lexical and grammar features distinguishing from a standard language. Through the language the Russian authors successfully create complicated, ambiguous artistic view of the world despite plain description. In total, further study of the Russian literature can broaden their knowledge about Russian culture, history and society.

\section{CONCLUSION}

One of the burning issues in teaching Russian for nonnative speakers is the problem of selecting authentic literary texts for reading by non-native readers of Russian. These literary pieces should simultaneously respect the requirements of the methodology of teaching Russian as a foreign language and be representative for the development of world literature canons, but also contribute to the acquisition of cultural and cross-cultural competences by students, since competencybased learning focuses on mastery of the set of these communicative and intercultural skills.

\section{References}

[1] A.N. Vasilyeva, Russian art literature in a foreign audience as a subject of study and as a material of language instruction, Moscow, MAPRYAL, 1972.
[2] M.G. Knipper, V.Y. Rosenzweig, "Lexico-semantic description of text adaptation," in Linguistics of text, vol. 1, Moscow, Maurice Thorez Moscow State Pedagogical Institute of Foreign Languages, 1974, pp. 131-136.

[3] L.S. Zhuravleva, M.D. Zinovieva, Learning to read (a case study of reading fiction texts), Moscow, Russian Language, 1984.

[4] T.E. Pecheritsa, Use of fictional text in teaching Russian as a foreign language, Moscow, Moscow State University Press, 1986.

[5] I.K. Gapochka, I read in Russian. Moscow, Russian Language, 1999.

[6] A.V. Brygina, Linguistic principles of adaptation of literary text, $\mathrm{PhD}$ Thesis, Moscow, 2005.

[7] I.G. Gubieva, V.A. Jacelenko, 50 Russian texts: Book for reading in Russian for foreigners, Moscow, Russian Course, 2008

[8] Y.L. Berezovskaya, O.I. Sharafutdinova, Russian as a foreign language: reading, Chelyabinsk, YuurSU, 2015.

[9] A.V. Rachkovskaya, "Fiction text in Russian as a foreign language classes: selection criteria and character of adaptation," in Ethnocultural and sociolinguistic aspects of theory and practice of language teaching, Minsk, BNTU, 2015, pp. 121-131.

[10] M.P. Chesnokova, "Teaching Reading Methodology," in Methodology of Teaching Russian as a Foreign language, Moscow, MADI, 2015, pp. 105-117.

[11] T.M. Dridze, Text activity in the structure of social communication, Moscow, Science, 1984

[12] E.V. Dziuba, S.A. Eremina, "Reading lesson for students learning Russian as a foreign language: teaching methods and methodology," Philological class, No 2 (52), pp. 109-117, 2018.

[13] H.D. Brown, "Learning a Second Culture," in J.M. Valdes (ed.), Culture Bound: Bridging the Culture Gap in Language Teaching, Cambridge, Cambridge University Press, 1986, p. 33

[14] L.B. Radin, Russian literature, Voronezh, Voronezh State University Press, 2002

[15] S.P. Malysheva, A.A. Tomilova, V.K. Tarnopolsky, Russian literature of the 18th century, Irkutsk, Irkutsk State University Press, 2007.

[16] T.V. Aleshka, Russian Literature of the First Half of the 20th Century 1920-1950s, Minsk, Bielorussian State University Press, 2009.

[17] I.I. Turina, A.E. Siskevich, Russian as a foreign language: professional sphere of communication. History of the Russian literature of the 20th century, Tomsk, Tomsk Polytechnic University Press, 2012.

[18] T.L. Vladimirova, Russian literature of the 20th century, Tomsk, Tomsk Pedagogical University Press, 2012

[19] V.G. Kasarov, M.L. Suponitskaya, Basics of Literature. From the history of Russian literature of the 19th century, Moscow, MADI, 2017.

[20] D.B. Gudkov, "Precedent Name in Cognitive Base of Modern Russian (Results of Experiment)," in Language, Consciousness, Communication, vol. 4, Moscow, Philology, 1998, pp. 82-93.

[21] V.A. Maslova, Cultural linguistics. Moscow, Publishing center "Academia," 2001, p. 87.

[22] E.Y. Chebotaryova, "Ethnic Characteristics of Students' Value Orientations," RUDN Journal of Psychology and Pedagogics, vol. 4, pp. 15-20, 2012.

[23] I.I. Yacenko, Russian "Non-traditional" prose of the late XX century. Saint Petersburg, Zlatoust, 2006, pp. 5-6.

[24] V.V. Aguenosov, "Teaching Russian literature for linguistic departments", in The World of Russian Word, No 3, pp, 72-74, 2011.

[25] Zh. Tiwu, H. Ruoqi, "Teaching Russian literature in Chinese universities: Problems and solutions," in Russian Language Abroad, No 4, pp. 109-116, 2011.

[26] N.V. Kulibina, Reading Russian poets' poems: the manual of training in reading fiction books, Saint Petersburg, Zlatoust, 2008, p. 8.

[27] Shamzi Zaynab Ali, Principles of selection of fiction texts in teaching Russian as a foreign language for Iraqi students, PhD Thesis, Moscow, 2013

[28] N.G. Chekalina, "Silver Age poetry in the system of teaching Russian as a foreign language," Grani poznania journal, No. 5, 2010. Retrieved on December 31, 2019 from: http://grani.vspu.ru/files/publics/241_st.pdf. 
[29] V.I. Karasik, Language circle. Personality. Concepts. Discourse. Moscow, Gnosis, 2004, pp. 306-307.

[30] A.M. Mirzabaeva, "Translations of Chekhov's Works into Foreign Languages,” Young Scientist, vol. 4, pp. 787-792, 2015.
[31] V.B. Kataev, Complexity of Simplicity. Stories and Plays by Chekhov, Moscow, Moscow State University Press, 1998. 